\title{
BMJ Open Cohort profile: CROSS-TRACKS: a population-based open cohort across healthcare sectors in Denmark
}

\author{
Anders Hammerich Riis (D) ,,2 Pia Kjær Kristensen, ${ }^{1,3}$ Matilde Grøndahl Petersen, ${ }^{1}$ \\ Ninna Hinchely Ebdrup, ${ }^{1,4}$ Simon Meyer Lauritsen, ${ }^{2,4}$ \\ Marianne Johansson Jørgensen ${ }^{1}$
}

To cite: Riis AH, Kristensen PK, Petersen MG, et al. Cohort profile: CROSS-TRACKS: a population-based open cohort across healthcare sectors in Denmark. BMJ Open 2020;10:e039996. doi:10.1136/ bmjopen-2020-039996

- Prepublication history and supplemental material for this paper is available online. To view these files, please visit the journal online (http://dx.doi. org/10.1136/bmjopen-2020039996).

Received 01 May 2020 Revised 28 September 2020 Accepted 07 October 2020

A) Check for updates

(C) Author(s) (or their employer(s)) 2020. Re-use permitted under CC BY-NC. No commercial re-use. See rights and permissions. Published by BMJ.

'Department of Research, Horsens Regional Hospital, Horsens, Denmark

${ }^{2}$ Enversion A/S, Aarhus,

Denmark

${ }^{3}$ Department of Clinical Epidemiology, Aarhus University Hospital, Aarhus, Denmark ${ }^{4}$ Department of Clinical Medicine, Aarhus University, Aarhus, Denmark

Correspondence to Mr Anders Hammerich Riis; anderiis@rm.dk

\section{ABSTRACT}

Purpose This paper describes the open cohort CROSSTRACKS, which comprises population-based data from primary care, secondary care and national registries to study patient pathways and transitions across sectors while adjusting for sociodemographic characteristics.

Participants A total of 221283 individuals resided in the four Danish municipalities that constituted the catchment area of Horsens Regional Hospital in 2012-2018. A total of $96 \%$ of the population used primary care, $35 \%$ received at least one transfer payment and $66 \%$ was in contact with a hospital at least once in the period. Additional clinical information is available for hospital contacts (eg, alcohol intake, smoking status, body mass index and blood pressure). A total of $23 \%$ ( $n=8191$ ) of individuals aged $\geq 65$ years had at least one potentially preventable hospital admission, and $73 \%(n=5941)$ of these individuals had more than one.

Findings to date The cohort is currently used for research projects in epidemiology and artificial intelligence. These projects comprise a prediction model for potentially preventable hospital admissions, a clinical decision support system based on artificial intelligence, prevention of medication errors in the transition between sectors, health behaviour and sociodemographic characteristics of men and women prior to fertility treatment, and a recently published study applying machine learning methods for early detection of sepsis.

Future plans The CROSS-TRACKS cohort will be expanded to comprise the entire Central Denmark Region consisting of 1.3 million residents. The cohort can provide new knowledge on how to best organise interventions across healthcare sectors and prevent potentially preventable hospital admissions. Such knowledge would benefit both the individual citizen and society as a whole.

\section{INTRODUCTION}

An increasingly ageing population and limited resources place new demands on society and healthcare. ${ }^{1}$ The global population of individuals aged $65+$ years is projected to increase from $8.2 \%$ in 2015 to $15.9 \%$ in 2050 , corresponding to $>1.5$ billion people. ${ }^{2}$ The elderly population has higher needs for healthcare compared with younger citizens. ${ }^{34}$ For example, the number of hospital

\section{Strengths and limitations of this study}

- The CROSS-TRACKS cohort is a population-based open cohort containing routinely collected data from both primary and secondary care combined with sociodemographic register data.

- The cohort is readily available for research projects: the data sources have already been linked, patient pathways have been identified, and data have been remodelled and prepared for cutting-edge use of artificial intelligence and to enable easier and simpler querying across source systems.

- The cohort is currently limited to the catchment area of Horsens Regional Hospital, but it covers both urban and rural areas and it has a total population of 221283 individuals by 2018 .

- The cohort will be expanded to include additional catchment areas in the Central Denmark Region, comprising a total population of 1.3 million individuals.

- The cohort offers new opportunities for health research by tracking the patients' pathway across healthcare sectors to provide new knowledge on the best way to organise future interventions.

admissions has increased by $45 \%$ from 2006 to 2018 among Danes aged $65+$ years. ${ }^{5}$ Therefore, Denmark and many other countries have reorganised the healthcare systems; they have reduced the number of hospital beds and shortened the length of hospital stays. The total number of days in a hospital bed has decreased by $16 \%$ from 2006 to $2018 .^{5}$ Therefore, an increasing part of the healthcare, treatment and rehabilitation services are provided by general practitioners (GPs) and the municipalities in the primary care setting.

One focus has been directed towards reducing the number of potentially avoidable readmissions. ${ }^{6}$ In the USA, almost $20 \%$ of discharged patients are readmitted to hospital within 30 days. ${ }^{7}$ This is costly to the individual citizens and to society. Special attention has 
been turned towards potentially preventable admissions and readmissions. These are often seen for ambulatory care sensitive conditions (ACSCs), which comprise conditions that can usually be treated and prevented in the primary care setting. ${ }^{8}$ More than $20 \%$ of hospital admissions among elderly US residents in nursing homes are estimated to concern ACSCs. ${ }^{9}$ In Denmark, $15 \%$ of all hospitalisations of the elderly population are expected to be preventable. ${ }^{10}$ The rates of potentially preventable hospital admissions are high in Denmark compared with other European countries. ${ }^{11}$ Furthermore, a recent study found higher rates of potentially preventable hospitalisations and readmissions for chronic medical conditions in Denmark compared with the USA. ${ }^{12}$ Consequently, there seems to be room for improvement in our approach to preventable admissions and readmissions.

Several interventions have aimed to reduce the risk of readmissions ${ }^{13}$ and to improve the care for discharged patients in the primary care setting. ${ }^{14}$ Most of these focused on the predischarge period (eg, patient education and discharge planning) or the postdischarge period (eg, follow-up telephone calls and home visits), whereas only few interventions bridged over both sectors (eg, patient-centred discharge instructions and transition coaching). The interventions bridging across sectors were most effective. ${ }^{13}$ This calls for studies of patient transitions across sectors in a population-based setting.

CROSS-TRACKS $^{15}$ is an open cohort comprising routinely collected administrative data from primary care, secondary care and national registries. The combined data sources allow us to explore key factors such as sociodemographic characteristics, labour market affiliation, social transfers, home-based nurse care, GP contacts and potential links between these factors and the use of services in secondary care.

The cohort is a valuable tool for studying patient pathways across sectors, including the patterns that characterise potentially preventable hospital admissions. This paper describes the new opportunities in healthcare research that are emerging from the comprehensive CROSS-TRACKS cohort.

\section{COHORT DESCRIPTION}

\section{Setting}

The tax-funded healthcare system in Denmark provides free access for all citizens to healthcare services. The five Danish regions are the backbone of the healthcare system, and they are responsible for organising and operating the somatic and psychiatric hospitals (figure 1). Furthermore, the regions reimburse GPs and specialists in private practice (eg, physiotherapists, psychologists or dentists) for dispensed prescriptions and services provided. ${ }^{16}$ The GPs can refer citizens to a wide range of welfare services (eg, home care and rehabilitation) that are provided in the primary care setting by the 98 municipalities under the regions. ${ }^{16}$ The catchment area usually comprises

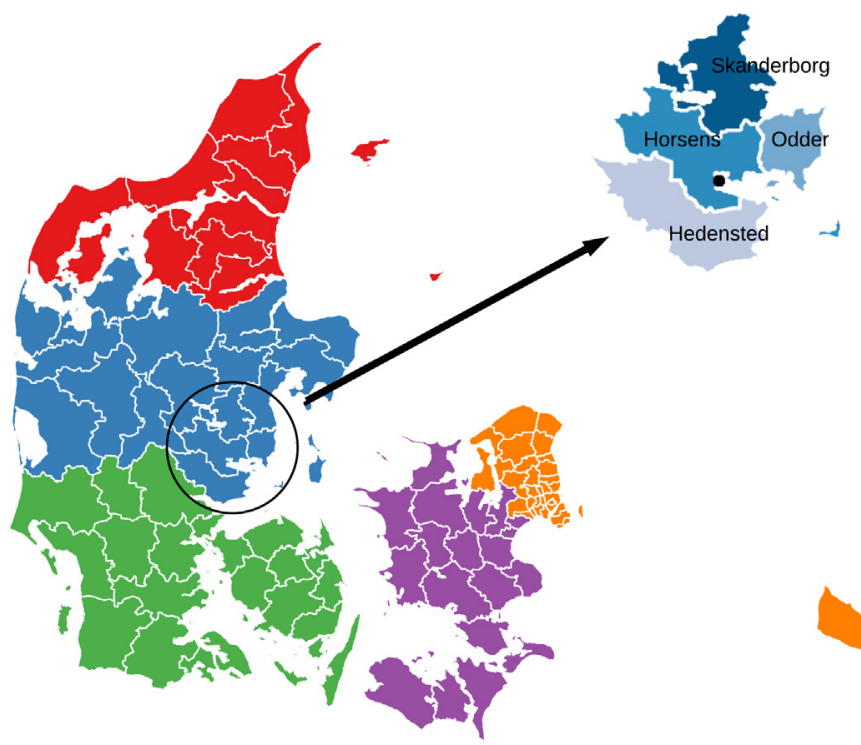

Figure 1 The five Danish regions and the 98 municipalities. The black circle indicates the four municipalities (Hedensted, Horsens, Odder and Skanderborg) included in the CROSSTRACKS cohort, and the black dot indicates the location of Horsens Regional Hospital.

the municipalities in the geographical area around the hospital.

The GP is the primary entry point into the healthcare system for Danish citizens, and the GP acts as a gatekeeper to secondary care, ${ }^{17}$ but the citizens can contact the prehospital directly for emergencies. Citizens have unrestricted access to dental care, which is free of charge for citizens below the age of 18. After hospital discharge, patients may be referred to the GP or a triage manager in the municipality for further treatment, care, or rehabilitation.

All Danish citizens receive a unique identifier at birth or immigration. This number is also referred to as the civil personal register (CPR) number. ${ }^{18}$ The CPR number enables electronic linkage for all data in the cohort across registries and databases. The cohort data are securely stored at the data warehouse of the Central Denmark Region in accordance with data protection regulations. The cohort is readily available for research projects as the data sources have already been linked and patient pathways have been identified. Further, the data have been remodelled according to the dimensional modelling principles laid out by Kimball and Ross, ${ }^{19}$ to provide a simple and consistent query interface across source systems.

As a rule, only anonymised data without the CPR number is provided to researchers. Researchers will receive an anonymised dataset that has already been linked and tailored to the individual project. Research projects that require additional linkage with other registry data can be provided with the CPR number. However, this is only possible on a secure server. In general, datasets must be securely stored, and the researchers must comply with research ethics guidelines. 

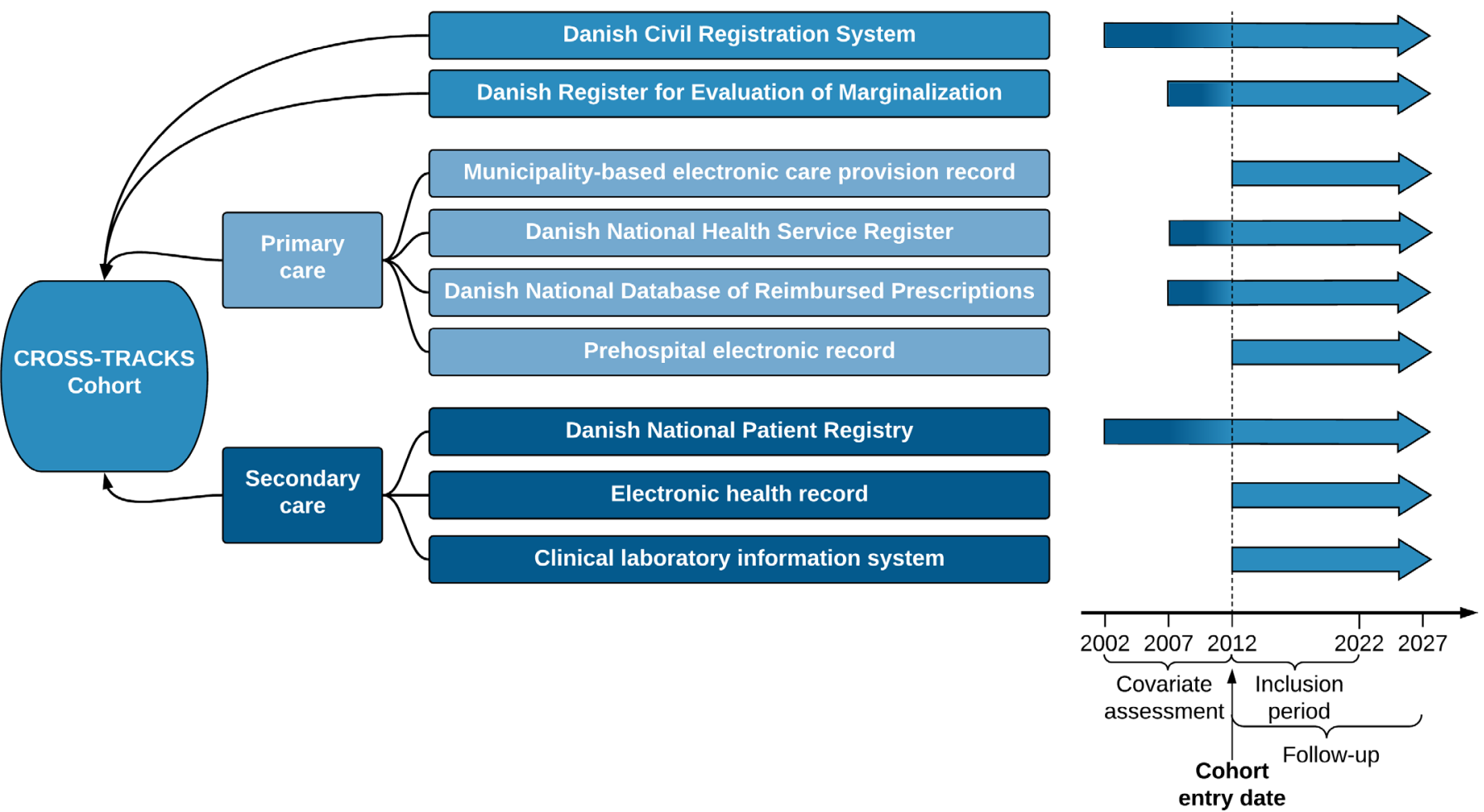

Figure 2 Data availability for the CROSS-TRACKS cohort in Denmark.

\section{Study population}

The CROSS-TRACKS cohort consists of all citizens aged $18+$ years residing in the catchment area of Horsens Regional Hospital, which comprises Hedensted, Horsens, Odder and Skanderborg municipalities (figure 1). The inclusion period started on 1 September 2012 (cohort entry date) and will last through 2022 (figure 2). Individuals are included on their 18th birthday or when moving to one of the four included municipalities. Individuals are followed from the date of inclusion until 5 years after the end of the inclusion period (31 December 2027) or date of death. Individuals moving away from these municipalities are followed for 5 years after the date of moving.

Patient characteristics are time-dependent because disease develops over time, and this affects the number and frequency of contacts with the healthcare system. The use of nationwide data sources ensures optimal adjustment for potential differences in patient characteristics, even for individuals living outside the included municipalities during part of the follow-up period. Moreover, we use look-back periods of lengths $5-10$ years to assess covariates prior to cohort entry date (figure 2 ). ${ }^{20}$

\section{Data collection}

Individuals are included in the cohort according to the inclusion criteria shown in the flow chart in figure 3.

\section{Administrative and health registries}

The CPR number originates from the Danish Civil Registration System (CRS) ${ }^{18}$ which also provides date of birth, gender, vital status, civil status, migration and place of residence. The CRS is updated on a daily basis with information on vital status and place of residence; this ensures complete follow-up for all individuals.

Weekly recordings of social benefits and other transfer incomes are retrieved from the Danish Register for Evaluation of Marginalisation (DREAM). ${ }^{21}$ DREAM can be used to categorise individuals into unemployed, on sick leave, receiving part-time benefit, receiving disability pension, or receiving retirement pension. ${ }^{22}$

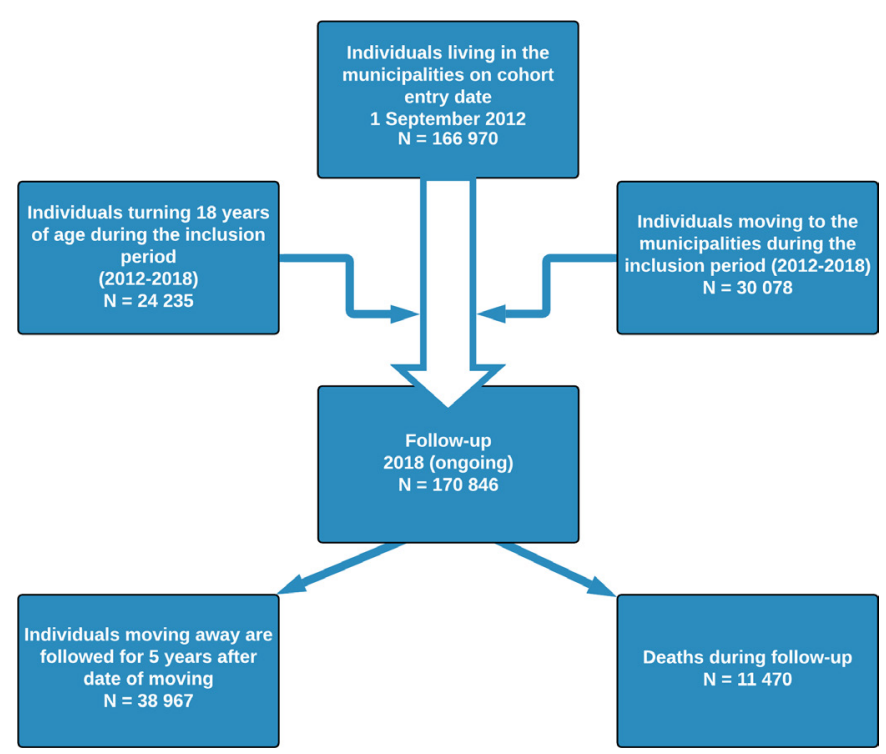

Figure 3 Flow chart of individuals included in the CROSSTRACKS cohort in Denmark 2012-2018. 


\section{Primary care}

The municipality-based electronic care provision record (ECPR) holds data on the health services granted to the citizens. These services comprise municipality-based practical help, rehabilitation assistance, personal care and home visits by a community nurse. The data includes the period (start and end dates) and total amount of time assigned to the services.

The Danish National Health Service Register holds information on contacts with healthcare professionals (eg, GP, dentist), type of consultation (eg, ordinary consultations, home visits, telephone consultations, electronic consultations), services provided (eg, paraclinical examinations, vaccination, pregnancy) and laboratory tests performed. ${ }^{23}$

The Danish National Database of Reimbursed Prescriptions contains detailed information on prescribed drugs that are partially reimbursed by the regions. This includes information on date of the redemption, number of pills, dose, number of defined daily doses, name and type of drug according to the Anatomical Therapeutic Chemical classification system. ${ }^{24}$

The prehospital electronic record holds information on treatment and transportation of patients by ambulance, medical cars or helicopters. Registrations include urgency level, date and time of departure and arrival, treatments, medications and a free-text field for additional information that may help ensure optimal transfer of patients to the hospital. ${ }^{25}$

\section{Secondary care}

The Danish National Patient Registry (DNPR) encompasses all hospital contacts, including admission date, discharge date and outpatient visits. Diagnoses, surgical procedures and examinations are registered according to the International Classification of Diseases. ${ }^{26}$ The main reason for each hospital contact is registered as the primary diagnosis, whereas secondary diagnoses are stated as other diseases in relation to the contact. Diagnoses registered in the DNPR can be used to identify individuals admitted to hospital with a primary ACSC-related diagnosis. In addition, the Charlson Comorbidity Index (CCI) score is calculated based on 19 conditions. ${ }^{27}$

The electronic health record (EHR) in the Central Denmark Region consists of healthcare-related registrations linked with date and time. The DNPR is based on registrations in the EHR, but this record contains additional data that are not transferred to the DNPR. This includes registrations on triage, patient's pulse, blood pressure, respiration frequency and microbiology test results. Some of these are used for early detection of critical illness. The EHR can also be used to identify patient-related lifestyle factors, such as diet, smoking and alcohol habits and physical activity. Furthermore, hospital-based drug treatment is registered in the EHR by the doctors prescribing the drug and the nurses administering the drug by dispensing the medicine to the patients.
The clinical laboratory information system consists of test results from blood and urine samples drawn by health professionals (in both primary care and hospitals) and analysed in clinical laboratories. ${ }^{28}$ Registrations include date of sample, health professional or hospital department requesting the analysis, requested assay or biomarker and corresponding nomenclature, properties and units code.

An overview of data sources and availability can be seen in figure 2 and table 1 . The codes used to extract the characteristics of citizens can be found in online supplemental material 1.

Although the EHR data in the data warehouse of the Central Denmark Region is updated on a daily basis, the combined cohort consisting of all data sources is only updated annually. The cohort is dynamic in the sense that the data quality is continuously improved as new research projects build on new sections of the cohort. See online supplemental material 2 for a description on how registrations on body mass index (BMI) was cleaned before use and online supplemental material 3 for a description on cleaning of blood pressure registrations.

\section{Follow-up}

Individual-level information during follow-up on diseases, treatments and administrative registrations is provided from the administrative and health registry data included in the cohort. Individuals are followed with respect to these registrations and their relevance to the study question for 5 years after the end of the inclusion period or from when they move away from the municipalities. Date of emigration or date of death is provided from the CRS.

\section{Population characteristics}

On the cohort entry date, 166970 individuals aged $18+$ years resided in the four municipalities. From 1 September 2012 through 2018, 24235 individuals turned 18 years of age, and 30078 moved to one of the municipalities. This yields a total population of 221283 individuals in the open cohort (figure 3). The main characteristics of citizens in the cohort are shown in table 2. Individuals aged below 18 years appear in the table, but they are not included in the cohort before their 18th birthday.

The catchment area of Horsens Regional hospital contained one health centre (located in Skanderborg), 69 GPs, 20 specialists in private practice, 11 chiropractors, 52 dentists, 45 physiotherapists, 25 podiatrists and 25 psychologists.

The largest municipality was Horsens with 78758 citizens, corresponding to $36 \%$ of the population on 1 September 2012. Skanderborg had 49160 (22\%) citizens, Hedensted had 39981 (18\%) citizens and Odder had 19493 (9\%) citizens. In the beginning of the inclusion period, Horsens was the only urban municipality, but Skanderborg went from rural to urban during the period.

The median age on cohort entry date was 41 years (IQR: 25-58 years) with an equal distribution of gender. The proportion of citizens who were married or living in 
Table 1 Administrative and health registries included in the CROSS-TRACKS cohort

\begin{tabular}{|c|c|c|c|}
\hline $\begin{array}{l}\text { Name and type of data } \\
\text { source and year of } \\
\text { initiation }\end{array}$ & $\begin{array}{l}\text { Description of data } \\
\text { source }\end{array}$ & Main variables & $\begin{array}{l}\text { Period of data inclusion in } \\
\text { the CROSS-TRACKS cohort }\end{array}$ \\
\hline $\begin{array}{l}\text { Danish Civil Registration } \\
\text { System, }{ }^{18} \text { administrative } \\
\text { registry, } 1968\end{array}$ & $\begin{array}{l}\text { Information on all } \\
\text { individuals residing in } \\
\text { Denmark }\end{array}$ & $\begin{array}{l}\text { CPR no (allowing linkage across all data sources) } \\
\text { Date of birth } \\
\text { Gender } \\
\text { Vital status (updated daily) } \\
\text { Civil status (updated daily) } \\
\text { Migration (updated daily) } \\
\text { Place of residence (updated daily) }\end{array}$ & $\begin{array}{l}1 \text { September 2002-31 } \\
\text { December } 2027\end{array}$ \\
\hline $\begin{array}{l}\text { Danish Register } \\
\text { for Evaluation of } \\
\text { Marginalisation, }{ }^{21} 22 \\
\text { administrative registry, } 1991\end{array}$ & $\begin{array}{l}\text { Weekly recordings of } \\
\text { transfer payments }\end{array}$ & $\begin{array}{l}\text { Reasons for receiving transfer payment } \\
\text { (unemployed, sick leave, part-time benefit, } \\
\text { disability pension, or retirement pension) } \\
\text { Dates for starting and ending transfer payment }\end{array}$ & $\begin{array}{l}1 \text { September } 2007-31 \\
\text { December } 2027\end{array}$ \\
\hline $\begin{array}{l}\text { Municipality-based } \\
\text { electronic care provision } \\
\text { record, health database, } \\
2012\end{array}$ & $\begin{array}{l}\text { Health services provided } \\
\text { by the municipalities to } \\
\text { citizens }\end{array}$ & $\begin{array}{l}\text { Type of service (assistance for home cleaning, } \\
\text { personal care, home visits by a community nurse, } \\
\text { or rehabilitation) } \\
\text { Subtype of service (eg, community nurses can } \\
\text { inject medicine, treat wounds, or measure vital } \\
\text { parameters) } \\
\text { Location of service provided (eg, citizen's own } \\
\text { home or nursing home) } \\
\text { Dates for starting and ending the service } \\
\text { Total amount of time assigned to the service }\end{array}$ & $\begin{array}{l}1 \text { September 2012-31 } \\
\text { December } 2027\end{array}$ \\
\hline $\begin{array}{l}\text { Danish National Health } \\
\text { Service Register, }{ }^{2336} \\
\text { administrative registry, } 1990\end{array}$ & $\begin{array}{l}\text { Contacts with healthcare } \\
\text { professionals }\end{array}$ & $\begin{array}{l}\text { Service provider (eg, GP, physiotherapist, dentist) } \\
\text { Type of consultation (ordinary consultations, } \\
\text { home visits, telephone consultations, or electronic } \\
\text { consultations via email or a secure website) } \\
\text { Service provided (eg, paraclinical examinations, } \\
\text { vaccination, pregnancy) } \\
\text { Laboratory tests performed } \\
\text { Amount of reimbursement } \\
\text { Date of the service } \\
\text { Dates for starting and ending treatment }\end{array}$ & $\begin{array}{l}1 \text { September } 2007-31 \\
\text { December } 2027\end{array}$ \\
\hline $\begin{array}{l}\text { Prehospital electronic } \\
\text { record, }{ }^{25} \text { health database, } \\
2012\end{array}$ & $\begin{array}{l}\text { Patient records from } \\
\text { emergency medical } \\
\text { services }\end{array}$ & $\begin{array}{l}\text { Type of transport (ambulance, medical car or } \\
\text { helicopter) } \\
\text { Urgency level } \\
\text { Distances } \\
\text { Addresses } \\
\text { Detailed patient journal included from 2017: } \\
\text { Information on treatments, medications, and } \\
\text { journal notes as free text } \\
\text { Date and time stamps for take offs and arrivals }\end{array}$ & $\begin{array}{l}1 \text { September } 2012-31 \\
\text { December } 2027\end{array}$ \\
\hline $\begin{array}{l}\text { Danish National Patient } \\
\text { Registry, }{ }^{2637} \text { administrative } \\
\text { registry, } 1977\end{array}$ & Hospital contacts & $\begin{array}{l}\text { Type of contact (inpatient or outpatient) } \\
\text { Acute versus scheduled } \\
\text { Hospital and department code } \\
\text { Diagnoses, surgical procedures and examinations } \\
\text { Diseases } \\
\text { Primary diagnosis and secondary diagnoses in } \\
\text { relation to the contact } \\
\text { Course of admission (since 2019) } \\
\text { Costs associated with the hospital contacts, } \\
\text { treatments, and procedures } \\
\text { Dates of admission and discharge for inpatients } \\
\text { Date of contact for outpatients }\end{array}$ & $\begin{array}{l}1 \text { September 2002-31 } \\
\text { December } 2027\end{array}$ \\
\hline
\end{tabular}

Continued 
Table 1 Continued

\section{Name and type of data source and year of} initiation

Electronic health record, health database, 2012

\section{Description of data} source

Secondary data source for the Danish National Patient Registry

\section{Clinical laboratory} information system, ${ }^{28}$ health database, 2000

\section{Main variables}

- Diagnoses, treatments, and examinations

- Structured registrations of healthcare content

- Triage

- Microbiology

- Standardised registrations on patient's pulse, blood pressure, respiration frequency etc. used for early detection of critical illness

- Registrations of patients' lifestyle factors regarding diet, smoking, alcohol and physical activity

- Recordings of patient's height and weight used for calculating body mass index. See online supplemental material 1 for details on data cleaning.

- Recordings of patient's blood pressure. See online supplemental material 1 for details on data cleaning.

- In-hospital medication: Doctor's orderings and nurses' dispensing's

- Meta data on updates of patient's electronical medication records shared by all Danish health professionals

- Journal notes as free text

- Date and time stamps of registrations

- Type of biological material

Laboratory test results from clinical laboratories

$>$

Identification of health pro department requesting the analysis

- NPU codes for types of tests requested (a blood specimen can by analysed for several different contents)

- Test results and units

Date and time of sample and test results

CPR, civil personal register; GP, general practitioner; NPU, nomenclature, properties and units.

a registered partnership was $44 \%$, and $44 \%$ of the citizens aged 18 years and above were living alone on cohort entry date.

During the inclusion period from 1 September 2012 through $2018,35 \%$ of the total population received some kind of transfer payment. Sick leave was the predominant reason with $10 \%$, which was followed by unemployment among $9 \%$ of the population.

A total of $21 \%$ had a CCI score of 1 or above at the end of the inclusion period. For the part of the population $(66 \%)$ with a hospital contact in the period from 1 September 2012 through 2018, we used registrations in the EHR to obtain the clinical characteristics. Early detection of critical illness was registered in the EHR among $43 \%$ of the population with at least one hospital contact. Registrations of blood pressure were used to identify patients with at least one registration of high blood pressure (49\%). Smoking status was recorded in $48 \%$ of individuals with at least one hospital contact, and $53 \%$ of these reported any smoking. Alcohol intake was registered in $40 \%$ with at least one hospital contact, and $30 \%$ of these had at least one incidence of intake above the recommendations of the health authorities, which is up to 7 drinks per week for females and 14 drinks per week for males. ${ }^{29}$ Of the 90385 patients with information on BMI, $50222(56 \%)$ were overweight $\left(\mathrm{BMI} \geq 25 \mathrm{~kg} / \mathrm{m}^{2}\right)$.

\section{Healthcare utilisation}

Almost everyone in the population received at least one service provided from primary care during the inclusion period. Daytime GP services were used by $95 \%$ of the population, dental services by $77 \%$ and psychologist services by $8 \%$ during the inclusion period. Municipalitybased care was provided to $13 \%$ of the citizens receiving rehabilitation assistance $(8 \%)$, and nursing care $(8 \%)$ was the most frequent service.

Antibiotics was the most frequently used type of prescription medication; $57 \%$ of the population redeemed at least one antibiotics prescription during the inclusion period. Non-steroidal anti-inflammatory (NSAID) prescriptions was redeemed by $37 \%$, and blood pressure lowering medication was used by $24 \%$ of the population.

A total of 42827 patient transportations were made by the prehospital in the period from 2017 to 2018; $26 \%$ were acute, $23 \%$ were urgent, and $49 \%$ had unknown urgency level. The transports concerned 18671 unique individuals, and 7786 individuals had more than one transport. Overall $66 \%$ of the population had at least one 
Table 2 Sociodemographic characteristics, clinical characteristics and healthcare utilisation among citizens in the four included Danish municipalities (Hedensted, Horsens, Odder and Skanderborg) in 2012-2018

$$
\text { N (\%) }
$$

\section{Sociodemographic characteristics}

Age at cohort entry date (1 September 2012)

Median age at cohort entry date, years

$41(25-58)$

(IQR)

$\begin{array}{ll}<18^{*} & 24235(11) \\ 18-39 & 80434(36) \\ 40-64 & 80288(36) \\ 65-79 & 28196(13) \\ 80+ & 8130(3.7)\end{array}$

Gender

\begin{tabular}{|c|c|}
\hline Female & $109267(49)$ \\
\hline Male & $112016(51)$ \\
\hline \multicolumn{2}{|l|}{ Municipality (on 1 September 2012) } \\
\hline Hedensted & 39981 (18) \\
\hline Horsens & $78758(36)$ \\
\hline Odder & $19493(8.8)$ \\
\hline Skanderborg & $49160(22)$ \\
\hline $\begin{array}{l}\text { Other (individuals moving to the four } \\
\text { municipalities after } 1 \text { September 2012) }\end{array}$ & 33891 (15) \\
\hline $\begin{array}{l}\text { Individuals moving away from the } \\
\text { municipalities }\end{array}$ & 38967 (18) \\
\hline
\end{tabular}

Marital status

\begin{tabular}{ll}
\hline Married or registered partnership & $97216(44)$ \\
\hline Divorced or dissolved partnership & $17859(8.1)$ \\
\hline $\begin{array}{l}\text { Widowed or longest living in a registered } \\
\text { partnership }\end{array}$ & $11077(5.0)$ \\
\hline Not married & $77815(35)$ \\
\hline Unknown & $17316(7.8)$ \\
\hline Living alone on cohort entry date† & $72967(44)$ \\
\hline Transfer payments & \\
\hline Any kind of transfer payment & $77410(35)$ \\
\hline Unemployment & $19849(9.0)$ \\
\hline Sick leave & $21873(9.9)$ \\
\hline State education grant & $13021(5.9)$ \\
\hline Maternity/paternity leave & $8356(3.8)$ \\
\hline Retirement pension & $8266(3.7)$ \\
\hline Disability pension & $1047(0.5)$ \\
\hline Social security benefits & $6996(3.2)$ \\
\hline Deaths during follow-up & $11470(5.2)$ \\
\hline Clinical characteristics &
\end{tabular}

Charlson Comorbidity Index score at the end of the inclusion period

\begin{tabular}{ll}
0 (no comorbidity) & $174159(79)$ \\
1 (low) & $21226(9.6)$ \\
\hline
\end{tabular}

Table 2 Continued

\begin{tabular}{ll}
\hline & N (\%) \\
\hline 2 (medium) & $13382(6.0)$ \\
\hline $3+$ (high) & $12516(5.7)$ \\
$\begin{array}{l}\text { Citizens with at least one hospital contact } \\
\text { (recorded in the electronical health records) }\end{array}$ & $147087(66)$ \\
Early detection of critical illness, total score & $63258(43)$ \\
Diastolic blood pressure & $102048(69)$ \\
Systolic blood pressure & $102085(69)$
\end{tabular}

High blood pressure (at least one registration 71029 (48) of diastolic $>90 \mathrm{~mm} \mathrm{Hg}$ or systolic $>140 \mathrm{~mm}$

$\mathrm{Hg}) \ddagger$

Pulseł

$100589(68)$

Respiratory rate‡

71904 (49)

Oxygen saturation $\ddagger$

$81096(55)$

Temperaturef

$71000(48)$

Smoking status $\ddagger$

70557 (48)

No smoking§

$32978(47)$

Any smoking§

$37579(53)$

Current smoker (at last registration)§

$17484(25)$

Occasional smoker (at last registration)§ 1216 (1.7)

Previous smoker (at last registration)§

$18879(27)$

Alcohol intakeł

$58833(40)$

Within recommendations; $\leq 7$ drinks for females, $\leq 14$ drinks for males $\rrbracket$

Above recommendations; $>7$ drinks for females, >14 drinks for males (any time) $\uparrow$

Body mass index (at least one registration) $\ddagger \quad 90384$ (61) $<18.5 \mathrm{~kg} / \mathrm{m}^{2 \star \star}$

$3202(3.5)$

$18.5-24.9 \mathrm{~kg} / \mathrm{m}^{2 \star *}$

$36961(41)$

$25-29.9 \mathrm{~kg} / \mathrm{m}^{2 * *}$

$30568(34)$

$30-34.9 \mathrm{~kg} / \mathrm{m}^{2 * *}$

$13068(14)$

$35-39.9 \mathrm{~kg} / \mathrm{m}^{2 \star *}$

$4451(4.9)$

$\geq 40 \mathrm{~kg} / \mathrm{m}^{2 \star *}$

2134 (2.4)

Triage of patients (at least one registration) $\ddagger \quad 43431$ (30)

Immediate resuscitation (red)†† 1474 (3.4)

Very urgent (orange)†† 9568 (22)

Urgent (yellow)†† $17516(40)$

Standard (green)††

14549 (33)

Non-urgent (blue)††

$324(0.75)$

\section{Healthcare utilisation}

Any health services from the municipalities 29158 (13)

Rehabilitation (eg, physiotherapy) 17118 (7.7)

Practical help (eg, home cleaning) 11692 (5.3)

Personal care (eg, weekly bath) 12419 (5.6)

Home visits by a community nurse (eg, 16709 (7.6) injection of medicine)

Any primary healthcare contact 


\section{Table 2 Continued}

\begin{tabular}{|c|c|}
\hline & $\mathrm{N}(\%)$ \\
\hline $\begin{array}{l}\text { Daytime face-to-face contact with general } \\
\text { practitioner }\end{array}$ & $210718(95)$ \\
\hline $\begin{array}{l}\text { Out-of-hours face-to-face contact with } \\
\text { general practitioner }\end{array}$ & $82684(37)$ \\
\hline Blood tests at general practitioner & $157689(71)$ \\
\hline Haemoglobin test at general practitioner & $106915(48)$ \\
\hline Spirometer test at general practitioner & $36164(16)$ \\
\hline Electrocardiograph at general practitioner & $81034(37)$ \\
\hline Talk therapy at general practitioner & $26869(12)$ \\
\hline Urine test at general practitioner & $92254(42)$ \\
\hline Rapid strep test at general practitioner & $46179(21)$ \\
\hline $\begin{array}{l}\text { C reactive protein test at general } \\
\text { practitioner }\end{array}$ & $132728(60)$ \\
\hline Other service at general practitioner & $208597(94)$ \\
\hline Chiropractor & $46345(21)$ \\
\hline Dentist & $171333(77)$ \\
\hline Physiotherapist & $66788(30)$ \\
\hline Podiatrist & $7170(3.2)$ \\
\hline Psychologist & $17527(7.9)$ \\
\hline \multicolumn{2}{|l|}{ Prescription medication } \\
\hline At least one prescription of antibiotics & $126280(57)$ \\
\hline At least one prescription of antidiabetics & $12577(5.7)$ \\
\hline At least one prescription of aspirins & $21613(9.8)$ \\
\hline $\begin{array}{l}\text { At least one prescription of blood pressure } \\
\text { lowering medication }\end{array}$ & $53127(24)$ \\
\hline At least one prescription of statins & $33837(15)$ \\
\hline $\begin{array}{l}\text { At least one prescription of proton pump } \\
\text { inhibitors }\end{array}$ & $47845(22)$ \\
\hline $\begin{array}{l}\text { At least one prescription of systemic } \\
\text { glucocorticoids }\end{array}$ & $25654(12)$ \\
\hline $\begin{array}{l}\text { At least one prescription of inhaled } \\
\text { corticosteroid therapy }\end{array}$ & $30999(14)$ \\
\hline At least one prescription of NSAIDs & $80944(37)$ \\
\hline At least one prescription of opioids & $34893(16)$ \\
\hline $\begin{array}{l}\text { At least one prescription of } \\
\text { antidepressants }\end{array}$ & $30491(14)$ \\
\hline At least one prescription of antipsychotics & $9767(4.4)$ \\
\hline $\begin{array}{l}\text { Urgency level among transports in 2017- } \\
2018 \text {, total no }\end{array}$ & 42827 \\
\hline Acute $(A) \ddagger \ddagger$ & $11181(26)$ \\
\hline 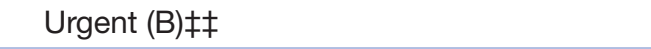 & $9637(23)$ \\
\hline 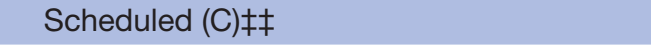 & $865(2.0)$ \\
\hline 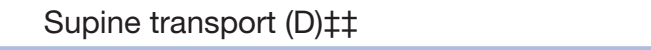 & $23(0.1)$ \\
\hline 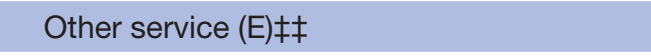 & $72(0.2)$ \\
\hline Urgency level unknownłł & $21049(49)$ \\
\hline \multicolumn{2}{|l|}{ Hospital contacts } \\
\hline At least one hospital contact & $147087(66)$ \\
\hline
\end{tabular}

Continued
Table 2 Continued

\begin{tabular}{ll} 
& $\mathbf{N}(\%)$ \\
\hline At least one inpatient hospital contact & $73791(33)$ \\
$\begin{array}{l}\text { At least one inpatient hospital contact with } \\
\text { acute admission }\end{array}$
\end{tabular}

At least one outpatient hospital contact

$134330(61)$

At least one emergency room visit

$59382(27)$

Emergency call to the prehospital resulting in 5624 (2.5) assistance by medical car

Emergency call to the prehospital resulting in $110(0.05)$ assistance by helicopter

Emergency call to the prehospital resulting in $339(0.15)$ no transportation

Potentially preventable admissions among 8191(23) individuals aged 65+ years

\begin{tabular}{ll} 
In-hospital medication ordering & 2778432 \\
\hline In-hospital medication dispensing & 12240606 \\
Biological samples & 4562264 \\
\hline Laboratory tests in clinical laboratories & 52607667 \\
\hline
\end{tabular}

Data are given as number (percentage of total population) or (percentage of subpopulation) during the inclusion period (1 September 2012 to 31 December 2018), unless otherwise specified.

*Included from their 18th birthday.

†Among 166970 individuals living in the municipalities aged 18 years and above.

$\ddagger$ Among 147087 individuals with at least one hospital contact. $\S$ Among 70557 individuals with at least one registration of smoking status.

ПAmong 58833 individuals with at least one registration of alcohol intake.

**Last registration among 90385 individuals with at least one registration of body mass index.

††Last registration among 43431 individuals with at least one registration of triage.

łłAmong 42827 transports in 2017-2018.

NSAID, non-steroidal anti-inflammatory.

hospital contact during the inclusion period, $33 \%$ had an inpatient contact, $61 \%$ had an outpatient visit, and $27 \%$ had an emergency room visit.

In the population of individuals aged $65+$ years, 8191 $(23 \%)$ had at least one potentially preventable hospital admission during the inclusion period; 5941 (73\%) of these had more than one potentially preventable hospitalisation.

Almost three million medications were ordered, and about 12 million medications were dispensed in the hospitals. Overall, 4.5 million biological samples were drawn, and 52 million laboratory tests were performed on these samples.

\section{FINDINGS TO DATE}

The CROSS-TRACKS cohort was established to gain greater research-based knowledge on the causes of potentially preventable (re)admissions by tracking patient 
pathways across healthcare sectors. The new knowledge can be used to strengthen the collaboration across sectors and to target joint efforts.

The cohort is currently being used for several ongoing health research projects. These include a prediction model for potentially preventable hospital admissions, a clinical decision support system based on artificial intelligence, prevention of medication errors in the transition between sectors, and health behaviour and sociodemographic characteristics of men and women in fertility treatment. Another study has applied machine learning methods for early detection of sepsis and has identified potential for initiating interventions earlier. ${ }^{30}$ In continuation of this study, the authors used explainable artificial intelligence to develop an early-warning score system for detection of acute critical illness. ${ }^{31}$ This study adds transparency in artificial intelligence by explaining which relevant EHR data predicts critical illness.

\section{STRENGTHS AND LIMITATIONS}

CROSS-TRACKS is the first cohort to provide readily available data from primary and secondary care for research projects: the data sources have already been linked, and patient pathways have been identified. A major strength of the cohort is the completeness and the high quality of the available data, which is obtained through the prospective collection of population-based data. In contrast to existing cohorts based on administrative registry data, ${ }^{16}$ the CROSS-TRACKS cohort provides comprehensive data on patient pathways including sociodemographic data and on results of diagnostic tests, medical treatments, care and rehabilitation at both settings, and patients' lifestyle factors. Therefore, CROSS-TRACKS offers both a broad focus on patients pathways, but can also be used for disease-specific research which is the aim of other cohorts (eg, Danish Centre for Strategic Research in Type 2 Diabetes (DD2) ${ }^{32}$ and The Predictors of Breast Cancer Recurrence (ProBe CaRE) Premenopausal Breast Cancer Cohort Study in Denmark ${ }^{33}$ ). An additional strength is that the unique Danish CPR number allows linkage across registers and complete follow-up for all individuals; this offers the possibility to monitor disease progression over time. The clinical information about the patients can be followed through the EHR when they live in the Central Denmark Region. If they move away, the DNPR can be used to follow the individual's disease development. Additionally, the 10-year look-back period and the follow-up through 2027 hold the possibility of following citizens for up to 25 years.

Given the detailed information on medication in both sectors, this cohort presents the complete history of registry-based drug use for each individual; this fosters rich opportunities for adjusting for confounders. Furthermore, the combination of psychiatric inpatient contacts, antidepressants and antipsychotics prescriptions, and talk therapy by GPs and psychologists offers potential for identifying psychiatric disease.
In addition, several validation studies have reported high validity of the Danish registry data. ${ }^{21}{ }^{2634}$ The cohort itself forms a basis for easy validation as the free-text registrations in the EHR are usually regarded as the gold standard to which registry information is compared.

Nevertheless, we note some limitations of the cohort. Not all data sources have yet been validated, and there are missing data on lifestyle characteristics, as they may not have been reported for all citizens in contact with a hospital. However, investigator bias is limited since much of the data is recorded by clinicians during diagnosis and treatment, and not for research purposes. The information on medication use in primary care is based on reimbursable redeemed prescriptions, whereas no information on over-the-counter medication is available. However, citizens with regular medication use have economic incentives to acquire the prescribed drugs because of the reimbursement option. Furthermore, a study on the use of aspirin and NSAIDs found that the potential for identifying medication use through prescription registries in Denmark is high. ${ }^{35}$

Another limitation is the missing data on treatments by private psychologists, physiotherapists and chiropractors; these services are not covered by the healthcare system. However, the private healthcare sector is small in Denmark and is mostly based on services eligible for reimbursement by the regions, and these services are thereby included in the registries. Additionally, private hospitals report to the DNPR, ${ }^{16}$ which also contributes to maintaining the high completeness of registry data.

The municipalities use different suppliers for reporting to the ECPR. This means that it requires extensive data management to streamline the information, and this could be a potential limitation. The inclusion of ECPR data is conducted in close collaboration with the municipalities and their data managers to ensure correct interpretation and high validity of the data.

Only the catchment area for Horsens Regional hospital is included in the cohort, and this may compromise the generalisability. However, the catchment area includes both urban and rural municipalities. In addition, citizen contacts with Aarhus University Hospital, which is located in the Central Denmark Region, are also included in the cohort through the recordings in the EHR. Because of the structure of the Danish national registries and databases, the cohort can easily be extended to comprise additional municipalities and regions and ultimately all of Denmark. Starting in 2020, we will expand the cohort to include all 1.3 million residents in the Central Denmark Region. This region consists of one university hospital, one psychiatric hospital, four hospitals with 24 hours emergency department, four hospitals without 24 hours emergency department, and ten health centres and acute clinics. ${ }^{16}$

The CROSS-TRACKS cohort provides valuable new opportunities for health research across primary and secondary care in the future; this is expected to benefit both the individual citizens and society as a whole. The cohort can contribute with new knowledge on how 
to organise interventions across sectors to reduce the number of potentially preventable (re)admissions.

Acknowledgements We gratefully thank the CROSS-TRACKS steering committee for initiating the project and providing access to the cohort. We also thank the Enversion A/S team for data acquisition, modelling, validation, and support.

Contributors AHR, PKK and MJJ wrote the first draft of the manuscript. MGP was responsible for data access. AHR performed the statistical analyses. MGP, NHE and SML provided critical review of the manuscript and all authors approved the final version.

Funding The project was supported by Horsens Regional Hospital, Fund for the advancement of health research in Central Denmark Region, the development and resource funds under Danish Regions (Udviklings- og forskningspuljen ved Danske Regioner), the Danish Health Confederation (Sundhedskartellet), Public Health in the Central Denmark Region - a collaboration between municipalities and the region (Folkesundhed i Midten), and Circular Co-Creation under the MedTec Innovation Consortium.

Map disclaimer The depiction of boundaries on the map(s) in this article does not imply the expression of any opinion whatsoever on the part of BMJ (or any member of its group) concerning the legal status of any country, territory, jurisdiction or area or of its authorities. The map(s) are provided without any warranty of any kind, either express or implied.

Competing interests None declared.

Patient and public involvement statement Patients and the public were not involved in the development of this research cohort.

Patient consent for publication Not required.

Ethics approval Register-based studies require no ethical approval in Denmark. The study was approved by the Danish Data Protection Agency (file numbers 200758-0010 and 2012-58-006) and the Danish Patient Safety Authority (file number 3-3013-1380/1, 3-3013-1380/2 and 3-3013-2741/1).

Provenance and peer review Not commissioned; externally peer reviewed.

Data availability statement No data are available. Access to CROSS-TRACKS data can be granted for research and analysis projects if certain criteria are met, and an application has been submitted to the steering committee. The committee strongly encourages national and international collaboration. For more information on access criteria and application form, see the website www.tvaerspor.dk (currently in Danish).

Supplemental material This content has been supplied by the author(s). It has not been vetted by BMJ Publishing Group Limited (BMJ) and may not have been peer-reviewed. Any opinions or recommendations discussed are solely those of the author(s) and are not endorsed by BMJ. BMJ disclaims all liability and responsibility arising from any reliance placed on the content. Where the content includes any translated material, BMJ does not warrant the accuracy and reliability of the translations (including but not limited to local regulations, clinical guidelines, terminology, drug names and drug dosages), and is not responsible for any error and/or omissions arising from translation and adaptation or otherwise.

Open access This is an open access article distributed in accordance with the Creative Commons Attribution Non Commercial (CC BY-NC 4.0) license, which permits others to distribute, remix, adapt, build upon this work non-commercially, and license their derivative works on different terms, provided the original work is properly cited, appropriate credit is given, any changes made indicated, and the use is non-commercial. See: http://creativecommons.org/licenses/by-nc/4.0/.

ORCID iD

Anders Hammerich Riis http://orcid.org/0000-0002-6684-4068

\section{REFERENCES}

1 Beard JR, Officer AM, Cassels AK. The world report on ageing and health. Gerontologist 2016;56:S163-6.

2 United Nations. Department of economic and social affairs. population dynamics. world population prospects 2019, 2019. Available: https://population.un.org/wpp/Download/Probabilistic/ Population/

3 Christensen K, Doblhammer G, Rau R, et al. Ageing populations: the challenges ahead. Lancet 2009;374:1196-208.

4 Sander M, Oxlund B, Jespersen A, et al. The challenges of human population ageing. Age Ageing 2015;44:185-7.
5 Statistics Denmark. Statistics Bank. Available: https://www. statistikbanken.dk/statbank5a/default.asp?w=3440 [Accessed 1 May 2020].

6 van Walraven C, Jennings A, Forster AJ. A meta-analysis of hospital 30-day avoidable readmission rates. J Eval Clin Pract 2012;18:1211-8.

7 Jencks SF, Williams MV, Coleman EA. Rehospitalizations among patients in the medicare fee-for-service program. $N$ Engl J Med 2009;360:1418-28.

8 Purdy S, Griffin T, Salisbury C, et al. Ambulatory care sensitive conditions: terminology and disease coding need to be more specific to aid policy makers and clinicians. Public Health 2009;123:169-73.

9 Mcandrew RM, Grabowski DC, Dangi A, et al. Prevalence and patterns of potentially avoidable hospitalizations in the US long-term care setting. Int J Qual Health Care 2016;28:104-9.

10 Kommunernes Landsforening [Local Government Denmark]; Danske Regioner [Danish Regions]; Finansministeriet [Danish Ministry of Finance]; Ministeriet for Sundhed og Forebyggelse [Danish Ministry of Health and Prevention]. Forebyggelse af indlæggelser. Synlige resultater. [Prevention of hospital admissions. Visible results] Danish, 2014. Available: https://sundhedsdatastyrelsen.dk/da/tal-oganalyser/analyser-og-rapporter/sundhedsvaesenet/synlige-resultater [Accessed 1 May 2020].

11 Thygesen LC, Christiansen T, Garcia-Armesto S, et al. Potentially avoidable hospitalizations in five European countries in 2009 and time trends from 2002 to 2009 based on administrative data. Eur J Public Health 2015;25 Suppl 1:35-43.

12 Schiøtz M, Price M, Frølich A, et al. Something is amiss in Denmark: a comparison of preventable hospitalisations and readmissions for chronic medical conditions in the Danish healthcare system and Kaiser Permanente. BMC Health Serv Res 2011;11:347.

13 Hansen LO, Young RS, Hinami K, et al. Interventions to reduce 30-day rehospitalization: a systematic review. Ann Intern Med 2011;155:520-8.

14 Hesselink G, Schoonhoven L, Barach P, et al. Improving patient handovers from hospital to primary care: a systematic review. Ann Intern Med 2012;157:417-28.

15 TVÆERSPOR [CROSS-TRACKS]Danish. Available: http://www. tvaerspor.dk/ [Accessed 1 May 2020].

16 Schmidt M, Schmidt SAJ, Adelborg K, et al. The Danish health care system and epidemiological research: from health care contacts to database records. Clin Epidemiol 2019;11:563-91.

17 Pedersen KM, Andersen JS, Søndergaard J. General practice and primary health care in Denmark. J Am Board Fam Med 2012;25 Suppl 1:S34-8.

18 Schmidt M, Pedersen L, Sørensen HT. The Danish civil registration system as a tool in epidemiology. Eur J Epidemiol 2014;29:541-9.

19 Kimball R, Ross M. The data Warehouse toolkit, the definitive guide to dimensional modeling. Wiley, 2013.

20 Riis AH, Johansen MB, Jacobsen JB, et al. Short look-back periods in pharmacoepidemiologic studies of new users of antibiotics and asthma medications introduce severe misclassification. Pharmacoepidemiol Drug Saf 2015;24:478-85.

21 Hjollund NH, Larsen FB, Andersen JH. Register-based follow-up of social benefits and other transfer payments: accuracy and degree of completeness in a Danish interdepartmental administrative database compared with a population-based survey. Scand J Public Health 2007;35:497-502.

22 Fonager K, Lundbye-Christensen S, Andreasen JJ, et al. Work status and return to the workforce after coronary artery bypass grafting and/or heart valve surgery: a One-Year-Follow up study. Rehabil Res Pract 2014;2014:1-6.

23 Andersen JS, Olivarius NDF, Krasnik A. The Danish National health service register. Scand J Public Health 2011;39:34-7.

24 Johannesdottir SA, Horváth-Puhó E, Ehrenstein V, et al. Existing data sources for clinical epidemiology: the Danish national database of Reimbursed prescriptions. Clin Epidemiol 2012;4:303.

25 Lindskou TA, Mikkelsen S, Christensen EF, et al. The Danish prehospital emergency healthcare system and research possibilities. Scand J Trauma Resusc Emerg Med 2019;27:100.

26 Schmidt M, Schmidt SAJ, Sandegaard JL, et al. The Danish national patient registry: a review of content, data quality, and research potential. Clin Epidemiol 2015;7:449-90.

27 Charlson ME, Pompei P, Ales KL, et al. A new method of classifying prognostic comorbidity in longitudinal studies: development and validation. J Chronic Dis 1987;40:373-83.

28 Grann AF, Erichsen R, Nielsen AG, et al. Existing data sources for clinical epidemiology: the clinical laboratory information system (LABKA) research database at Aarhus University, Denmark. Clin Epidemiol 2011;3:133-8. 
29 Sundhedsstyrelsens udmeldinger om alkohol [The Danish Health Authority's statements about alcohol intake]. Danish. Available: https://www.sst.dk/da/viden/alkohol/alkoholforebyggelse/ sundhedsstyrelsens-udmeldinger-om-alkohol [Accessed 1 May 2020].

30 Lauritsen SM, Kalør ME, Kongsgaard EL, et al. Early detection of sepsis utilizing deep learning on electronic health record event sequences. Artif Intell Med 2020;104:101820.

31 Lauritsen SM, Kristensen M, Olsen MV, et al. Explainable artificial intelligence model to predict acute critical illness from electronic health records. Nat Commun 2020;11:3852.

32 Christensen DH, Nicolaisen SK, Berencsi K, et al. Danish centre for strategic research in type 2 diabetes (DD2) project cohort of newly diagnosed patients with type 2 diabetes: a cohort profile. BMJ Open 2018;8:e017273.
33 Collin LJ, Cronin-Fenton DP, Ahern TP, et al. Cohort profile: the predictors of breast cancer recurrence (probe care) premenopausal breast cancer cohort study in Denmark. BMJ Open 2018;8:e021805.

34 Riis $\mathrm{AH}$, Erichsen R, Ostenfeld EB, et al. Validating registry data on statins prescriptions by blood measurements. Pharmacoepidemiol Drug Saf 2019;28:609-15.

35 Schmidt M, Hallas J, Friis S. Potential of prescription registries to capture individual-level use of aspirin and other nonsteroidal antiinflammatory drugs in Denmark: trends in utilization 1999-2012. Clin Epidemiol 2014;6:155.

36 Schou Pedersen H, Fenger-Grøn M, Bech BH, et al. Frequency of health care utilization in the year prior to completed suicide: a Danish nationwide matched comparative study. PLoS One 2019;14:e0214605.

37 Lynge E, Sandegaard JL, Rebolj M. The Danish national patient register. Scand J Public Health 2011;39:30-3. 